\title{
Role of the azygos venous system in the investigation of portal hypertension
}

\author{
M. JOHN MURRAY ${ }^{1}$ \\ From the University of Minnesota Department of Medicine, \\ Minneapolis, Minnesota, U.S.A.
}

EDITORIAL SYNOPSIS The azygos venous system is a 'final common path' for the return of portal blood to the systemic circulation in subjects with portal hypertension and an extensive collateral circulation. The author suggests that catheterization of the vena azygos major, which he has performed in the dog, can provide useful information and mirror changes in portal vein blood in dogs with portal hypertension. The higher oxygen and ammonia content and the fall of elevated azygos venous pressure after pitressin suggest this theory. Further detection of 'marker' substances such as ${ }^{131}$ I Rose Bengal and ${ }^{133}$ Xenon in azygos blood could perhaps form a basis for the estimation of collateral circulation following their instillation into the jejunum. Perhaps these techniques can be translated for the human subject with portal hypertension. The author feels that they can.

The portal venous system in man and animals is not directly accessible without operation except occasionally through a superficial abdominal collateral (Bean, Franklin, Embick, and Daum, 1951). A close approximation of portal venous pressure may be obtained from an hepatic wedge pressure (Myers and Taylor, 1951), or a splenic pulp pressure (Atkinson and Sherlock, 1954) but these routes do not readily permit chemical, biological, or flow studies on portal venous blood. The interposition of the liver between portal and systemic venous circuits leads to modification by the hepatic cells of materials reaching the systemic from the portal system. It seems likely that the azygos system might provide more direct access to the portal system when portal hypertension with significant collateral flow is present. Without the changes imposed on the portal venous blood by the liver, the chemical and dynamic findings in the azygos system may reflect more accurately the state of the portal venous system. When it was found that the vena azygos major could be readily and consistently catheterized, it was planned to study this system in normal dogs and dogs with portal hypertension. To establish good collateral flow through the azygos system the procedures described by Tamiya and Thal (1960) were employed in dogs.

The study was divided into two parts: the collection of data in normal dogs and the collection of

'Supported by the U.S.P.H.S. grant no. HE 06881-04 and the Minnesota Heart Assocation. data in dogs with extensive collateral systems. In each group the following observations were made.

A The pressure in the lowest reaches of the azygos vein before and after the administration of pitressin; $B$ the pressure in the hepatic vein wedge position before and after pitressin; $\mathrm{C}$ determination of the haemoglobin, blood oxygen content and saturation, catecholamines, serotonin, and ammonia in samples of blood obtained from azygos and hepatic veins; $D$ the appearance time and concentration of sodium fluorescin, ${ }^{133}$ Xenon, and ${ }^{131} \mathbf{I}$ Rose Bengal in hepatic and azygos venous blood after instillation of each material into the jejunum; E the appearance time of ${ }^{133}$ Xenon in the lymph from the thoracic duct after the instillation in the jejunum; $F$ retrograde venography of the azygos system.

\section{METHOD}

PREPARATION OF ANIMALS Normal dogs of approximately $15 \mathrm{~kg}$. were used. Under intravenous pentobarbital anaesthesia the production of collateral circulation was achieved by a modification of the procedure of Tamiya and Thal (1960). First the spleen was removed and a side-to-side anastomosis established between the splenic artery and vein. Approximately one month later the portal vein was located and obstructed to about one quarter of its calibre with a silk ligature. The mortality of the operation was near $75 \%$. The surviving dogs were studied between one and two months after the second stage. 
INVESTIGATION OF ANIMALS Both groups were fasted and anaesthetized with intravenous pentobarbital. Two $50 \mathrm{~cm}$. Gooddale-Lubin woven dacron cardiac catheters no. 5F were introduced through the external jugular vein under fluoroscopy. One was passed through the right atrium into the hepatic vein in readiness for the wedge procedure. The other was advanced slowly along the superior vena cava with the tip pointed posteriorly. Entrance into the vena azygos major was readily achieved in most instances and the catheter tip was then pushed as far down the azygos vein as possible without entering an intercostal vein. The progress of the catheter was usually impeded at about $25 \mathrm{~cm}$. when it appeared to be located just below the margin of the thorax. At this point, pressures were recorded with a Statham strain gauge P-23db on a four channel Sanborn recorder before and after the intravenous injection of 20 units of pitressin in $1 \mathrm{ml}$. Pressures were recorded simultaneously in the hepatic wedge position. In both positions blood samples were obtained for the determination of haemoglobin oxygen content (Van Slyke technique), catecholamines (WeilMalherbe and Bone, 1952), serotonin (Udenfriend, Weissbach, and Brodie, 1958), and ammonia (Faulkner and Britton, 1960).

The appearance time and concentration curves of sodium fluorescin, ${ }^{133}$ Xenon, and ${ }^{131} \mathrm{I}$ Rose Bengal in hepatic and azygos vein blood following instillation of these materials into the jejunum were determined as follows. An infant-size Leonard tube with a coiled spring stylet manufactured by Phalen of Minneapolis was passed under fluoroscopy into the upper jejunum. First, $0.25 \mathrm{~g}$. sodium fluorescin in $5 \mathrm{ml}$. of water was injected down the Leonard tube followed by a further $10 \mathrm{ml}$. of water as a flushing dose. Samples of blood, $0.5 \mathrm{ml}$., were taken from both venous sites at $5,10,20,30,40,50$, and 60 minutes. From each sample $0 \cdot 1 \mathrm{ml}$. of serum was obtained and diluted with $10 \mathrm{ml}$. of weak base and read in a photofluorimeter. Next 0.3 mc of ${ }^{133}$ Xenon was dissolved in $5 \mathrm{ml}$. of saline in a capped syringe. The syringe contents were then injected down the tube and followed by $10 \mathrm{ml}$. of saline as a flushing dose. The tube was clamped to prevent escape of gas. Samples of blood, each of $2 \mathrm{ml}$, were obtained in capped syringes from both sites at the same intervals as above. In the untreated dogs $2 \mathrm{ml}$. of femoral artery blood was obtained by puncture to check for the presence of ${ }^{133}$ Xenon in the systemic arterial circuit. All samples were counted three times in a well scintillation counter at $80 \mathrm{KeV}^{5}$ for a total of 10,000 disintegrations. One $\mu \mathrm{c}$. of ${ }^{131} \mathrm{I}$ Rose Bengal containing approximately $10 \mu \mathrm{g}$. of Rose Bengal dye was injected down the tube and $2 \mathrm{ml}$. samples obtained from the hepatic and azygos veins at the intervals described were counted in a well scintillation chamber in a similar manner at $384 \mathrm{KeV}$.

The thoracic duct was dissected in the neck and the largest calibre polyethylene tube possible tied into the duct. The lymph was allowed to drain continuously at approximately $0.5 \mathrm{ml}$./per $\mathrm{min}$. into gas-tight closed sample collectors which were replaced at $5,20,40,60$, 80,100 , and 120 minute intervals. The samples were counted in the well scintillation counter at $80 \mathrm{KeV}$ for 10,000 disintegrations and then the volumes measured.
Lastly, $10-20 \mathrm{ml}$. of $50 \%$ sodium diatrizoate was injected forcibly by hand down the azygos catheter and radiographs were taken at five per second with a cassette changer in an attempt to outline the communications between the portal and azygos systems.

\section{RESULTS}

It was clear that in the 12 dogs with portal hypertension, the azygos vein pressures reflected the pressure changes in the portal vein and paralleled the pressures obtained in the hepatic wedge position. Despite the unusual nature of the portal hypertension, with its large arterial component, there was a surprising reduction in azygos and hepatic venous pressure following the intravenous injection of pitressin (Table I). As was expected from the

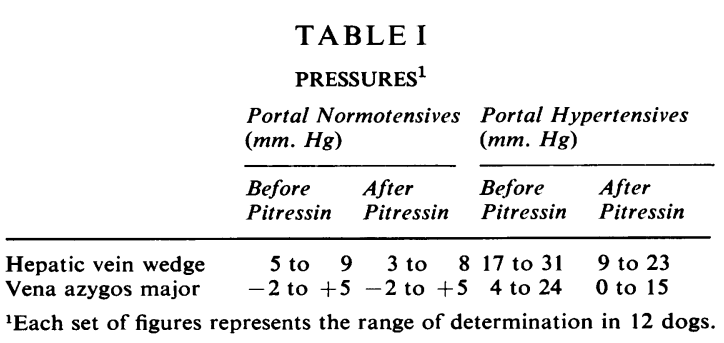

previous investigation of a young man with a spontaneous splenic arteriovenous fistula (Murray, Thal, and Greenspan, 1960), the blood from the azygos vein in the dogs with portal hypertension showed increased arterial oxygen content and saturation, but there was no such increase in the hepatic vein blood (Table II).

TABLE II

BLOOD OXYGEN CONTENT AND OXYGEN SATURATION ${ }^{1}$

Portal Normotensives Portal Hypertensives

\begin{tabular}{lllll}
\cline { 1 - 1 } $\begin{array}{l}\text { Oxygen } \\
\text { Content }\end{array}$ & $\begin{array}{l}\text { Satur- } \\
\text { (vol. } \%)\end{array}$ & $\begin{array}{l}\text { Oxygen } \\
\text { ation }\end{array}$ & $\begin{array}{l}\text { Content } \\
(\mathrm{\%})\end{array}$ & $\begin{array}{l}\text { Satur- } \\
\text { ation }\end{array}$ \\
$(\%)$
\end{tabular}

Hepatic vein wedge $\quad 13.6$ to 15.271 to 7713.4 to 15.270 to 77 $\begin{array}{lllll}\text { Vena azygos major } 13 \text { to } 14.7 & 66 \text { to } 73 & 15.8 \text { to } 17.5 & 78 \text { to } 89\end{array}$

${ }^{1}$ Each set of figures represents the range of determinations in 12 dogs'

Blood samples from venous sites in both groups of animals failed to show the presence of either catecholamines or serotonin. However, dogs on their normal diet of Purina dog chow, which contained an average of $52 \mathrm{~g}$. of protein per day, showed a significant rise in blood ammonia levels in the azygos and hepatic veins when they had a collateral circulation. The rise was greater in the azygos samples. 
TABLE III

CATECHOLAMINES, SEROTONIN, AND AMMONIA CONTENT OF AZYGOS AND HEPATIC VEIN BLOOD ${ }^{1}$

\begin{tabular}{|c|c|c|c|c|c|c|}
\hline & \multicolumn{3}{|c|}{ Portal Normotensives } & \multicolumn{3}{|c|}{ Portal Hypertensives } \\
\hline & Catecholamines & Serotonin & $\begin{array}{l}\text { Ammonia } \\
(\mu \mathrm{g} . \%)\end{array}$ & Catecholamines & Serotonin & $\begin{array}{l}\text { Ammonia } \\
(\mu g . \%)\end{array}$ \\
\hline $\begin{array}{l}\text { Hepatic vein wedge } \\
\text { Vena azygos major }\end{array}$ & $\begin{array}{l}\text { None } \\
\text { None }\end{array}$ & $\begin{array}{l}\text { None } \\
\text { None }\end{array}$ & $\begin{array}{l}33-107 \\
27-105\end{array}$ & $\begin{array}{l}\text { None } \\
\text { None }\end{array}$ & $\begin{array}{l}\text { None } \\
\text { None }\end{array}$ & $\begin{array}{l}37-175 \\
84-226\end{array}$ \\
\hline
\end{tabular}

${ }^{1}$ Each set of figures represents the range of determination in 12 dogs.

The arrival time and concentration of various indicator substances in the hepatic and azygos veins after instillation in the jejunum were first checked by small pilot studies in two dogs anaesthetized with pentobarbital. The abdomens were opened and $0.3 \mathrm{mc}$. of ${ }^{133}$ Xenon and $1 \mu \mathrm{c}$. of ${ }^{{ }^{131} \mathrm{I}}$ Rose Bengal respectively were injected directly through the jejunal wall with a 22 gauge needle. Samples of portal venous and femoral arterial blood for counting were obtained from the largest calibre polyethylene tubing which could be inserted in those vessels. From these studies it was evident that both substances were absorbed quickly. ${ }^{133}$ Xenon was chosen for trial, because an indicator was required which did not undergo significant recirculation after its first passage through the lungs in the normal animals. That this was so was proven by the absence of significant activity in the femoral arterial samples. ${ }^{131}$ I Rose Bengal was also chosen because it seemed likely that the liver in normal animals might be able to extract the minute dose of the dye (as it reached the liver via the portal vein) and prevent its systemic circulation. One $\mu \mathrm{c}$. of this material contains less than $10 \mu \mathrm{g}$. of dye. Activity from ${ }^{131} \mathrm{I}$ should not then be detectable in the arterial circuit unless the ${ }^{131}$ I was released from the dye in the gut or during its passage through the gut wall. The pilot study showed no significant activity above background in the femoral artery sample. Sodium fluorescin was chosen as the third indicator as patterns of arrival time and concentration had already been established in portal and systemic venous blood (Blondheim and Kunkel, 1950).

Since it has been observed that there is an increase in the flow of thoracic duct lymph in portal hypertension (Dumont and Mulholland, 1960), it seemed reasonable to expect some of the indicator materials to appear in that system. A pilot study consisting of the direct injection of ${ }^{133}$ Xenon into the jejunal lumen as described above plus the collection of lymph from the thoracic duct confirmed this likelihood.

Twelve normal dogs and 12 dogs with wellestablished portal-azygos collaterals were studied after instillation into the jejunum through the Leonard tuke of the three materials discussed. Following instillation of ${ }^{133}$ Xenon, in the normal dogs activity appeared in the hepatic vein samples, but not in femoral artery or azygos samples. In the portal hypertensive animals the activity appeared in high concentration in the azygos vein, but the rise in the hepatic vein activity was smaller and later than in the normal animals, presumably due to the surgical narrowing of the portal veins (Fig. 1). No activity was noted in the femoral artery after instillation of ${ }^{131}$ I Rose Bengal. No activity appeared in the hepatic azygos vein samples in normals. In the portal hypertensive group, activity appeared both in the azygos and femoral artery samples (Fig. 2).

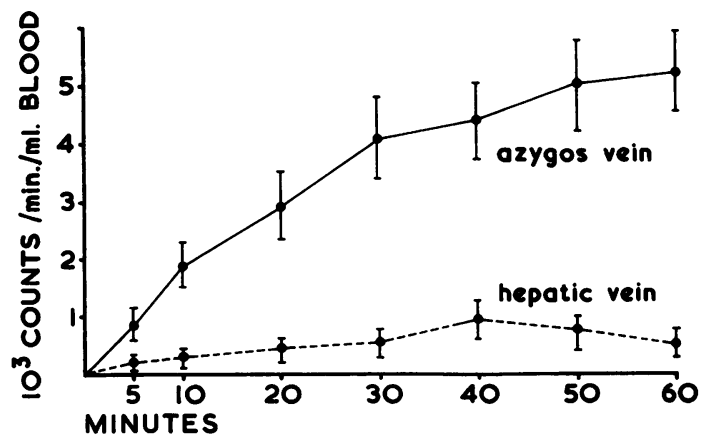

FIG. 1. Activity in azygos and hepatic veins of portal hypersensitive dogs after instillation of $0.3 \mathrm{mc} .{ }^{133}$ Xenon into the jejunum. The vertical bars represent the maximum and minimum observations on 12 dogs.

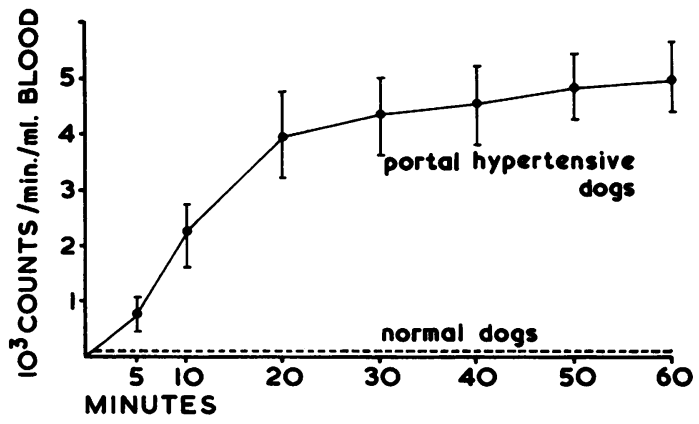

FIG. 2. Activity in azygos blood after instillation of $1 \mu \mathrm{c}$. ${ }^{131}$ I Rose Bengal into jejunum. Vertical bars represent maximum and minimum observations on 12 dogs. 


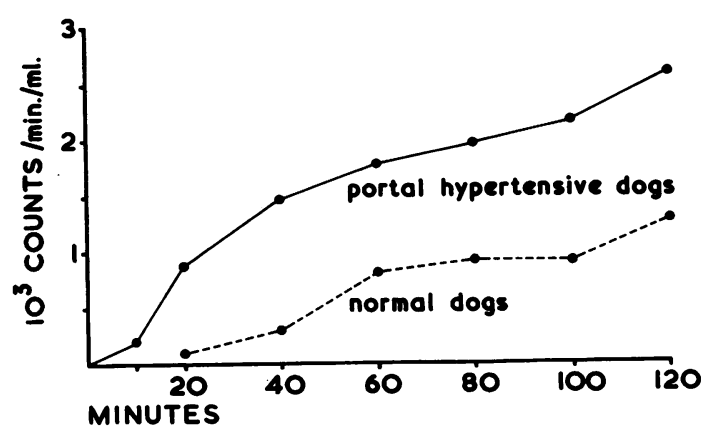

FIG. 3. Activity in thoracic duct lymph after instillation of ${ }^{133}$ Xenon into the jejunum. Each point represents the mean of determinations in 12 dogs.

The earlier appearance time and higher concentration of sodium fluorescin was characteristic of the portal hypertensive dogs when compared with normals (Fig. 3). In the thoracic duct study the ${ }^{133}$ Xenon appeared earlier and in higher concentrations in the experimental animals than in normals (Fig. 4). Three animals only were studied by this method. Retrograde venography of the azygos system failed to outline the communication of the ayzgos and portal systems.

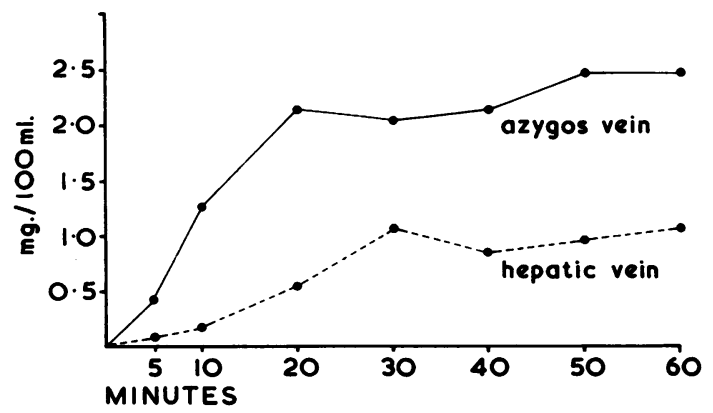

FIG. 4. Blood levels of sodium fluorescin after instillation of $0.25 \mathrm{~g}$. into the jejunum. Each point represents the mean of determinations in three dogs.

\section{DISCUSSION}

The type of portal hypertension in the dogs under study was unusual because of the large shunt from splenic artery to splenic vein. This procedure was necessary to establish good collateral circulation (Tamiya and Thal, 1960), but as a consequence a large amount of highly saturated blood entered the azygos system. It is known, however, that portal venous blood in normal humans has a greater oxygen content than other peripheral veins (Smythe, Fitzpatrick, and Blakemore, 1951) and that this content is even higher in patients with portal hypertension from Laennec's cirrhosis (Longmire, 1957). This latter phenomenon may be due to a flow of arterial blood from the hepatic, retrogradely into the portal, vein (Child, 1957). It appears likely then that the finding of a higher than normal oxygen content in the azygos system in humans may be presumptive evidence of portal-azygos collaterals with portal hypertension.

Since the end azygos vein pressures in this study paralleled the hepatic vein wedge pressure this determination might be useful in cirrhosis in gauging portal venous pressure. It is true that there must be a large arterial contribution to the azygos pressure in these experimental animals but the significant drop in pressure after injection of pitressin suggests that there is also a strong venous component to the pressure rise. Furthermore, in the patients with portal cirrhosis we have studied to date, there is the same parallel between hepatic wedge and end azygos pressure that is seen in the dog.

Failure to detect catecholamine and serotonin in hepatic and azygos samples suggested that either these substances were not produced excessively in the portal system in acquired portal hypertension, or that the methods used were too insensitive to detect them. It was not surprising to find increased levels of ammonia in dogs with collaterals and it seemed likely that the difference between the hepatic vein and the azygos samples was an index of the amount of shunting through the azygos.

The appearance time and concentration curves of the three indicators at the respective sampling sites provided evidence that it is possible with azygos catheterization and jejunal intubation to determine the presence and crudely quantitate the amount of collateral flow from the portal system into the azygos system.

\section{SUMMARY}

A study was conducted on dogs with experimentally produced portal-systemic collaterals and portal hypertension to decide if azygos vein catheterization was a useful approach to the study of portal hypertension with collateral flow. Azygos catheterization was found to be both a practical procedure and a reliable indicator of portal pressure. Increased ozygen content of the azygos blood appeared to be a sign of collateral flow. No increase in catecholamine or serotonin in azygos blood could be found but the ammonia content was higher in the animals with collateral flow than in control animals. Using indicator substances instilled into the jejunum the 
collateral circulation could be readily detected and quantitated crudely by sampling from the azygos and hepatic veins. It would appear that these methods are entirely applicable to humans and preliminary studies in patients with cirrhosis support this hypothesis.

\section{REFERENCES}

Atkinson, M., and Sherlock, S. (1954). Intrasplenic pressure as index of portal venous pressure. Lancet, 1, 1325-1327.

Bean, W. B., Franklin, M., Embick, J. F., and Daum, K. (1951), Absorption studies using portal anastamotic vein. J. clin. Invest., 30, 263-273.

Blondheim, S. H., and Kunkel, H. G. (1950). Portal blood in collateral veins of patients with cirrhosis. Acetylation by the intestine. Proc. Soc. exp. Biol. (N.Y.), 73, 38-41.

Child, C. H. (1957). In discussion to Taylor, F. W. (1957).

Dumont, A. E., and Mulholland, J. H. (1960). Flow rate and composition of thoracic duct lymph in patients with cirrhosis. New Engl. J. Med., 263, 471-474.
Faulkner, W. R., and Britton, R. C. (1960). The determination of blood ammonium by a modification of the Conway technic. Cleveland Clin. Quart., 27, 202-214.

Longmire, W. (1957). In discussion to Taylor, F. W. (1957).

Murray, M. J., Thal, A. P., and Greenspan, R. (1960). Splenic arteriovenous fistulas as a cause of portal hypertension. Amer. J. Med., 29, 849-856.

Myers, J. D., and Taylor, W. J. (1951). An estimation of portal venous pressure by occlusive catheterization of an hepatic venule. J. clin. Invest., 30, 662-663.

Smythe, C. McC., Fitzpatrick, H. F., and Blakemore, A. H. (1951). Studies of portal venous oxygen content in unanaesthetized man. Ibid., 30, 674.

Tamiya, T., and Thal, A. P. (1960). Esophageal varices produced experimentally in the dog. Surg. Gynec. Obstet., 111, 147-154.

Taylor, F. W. (1957). Experimental hypertension portal. Ann. Surg., 146, 683-690.

Udenfriend, S., Weissbach, H., and Brodie, B. B. (1958). Assay of serotonin and related metabolites, enzymes, and drugs. In Meth. biochem. Anal., 6, 95-130.

Weil-Malherbe, H., and Bone, A. D. (1952). Chemical estimations of adrenaline-like substances in blood. Biochem. J., 51, 311-318.

\section{The December 1965 Issue}

\section{THE DECEMBER 1965 ISSUE CONTAINS THE FOLLOWING PAPERS}

Crohn's disease of the anal region B. K. GRAY, H. E. LOCKHART-MUMMERY, and B. C. MORSON

A comparative study of the effects of gastrin, histamine, histalog, and mechothane on the secretory capacity of the human stomach in two normal subjects over 20 months G. M. MAKHLOUF, J. P. A. MCMANUS, and W. I. CARD

Secretory function of Barrett's epithelium N. B. HERSHFIELD, J. F. LIND, J. A. HILDES, and L. S. MCMORRIS

Study of gastric acid secretion in hookworm duodenitis S. RAJU and F. M. NARIELVALA

Observations on 205 confirmed cases of acute pancreatitis, recurring pancreatitis, and chronic pancreatitis HENRI SARLES, JEAN-CLAUDE SARLES, ROGER CAMATTE, RAYMOND MURATORE, MICHEL GAINI, CLAUDE GUIEN, JEAN PASTOR, and FRANÇOISE LE ROY

Radiation enteritis with malabsorption H. I. TANKEL, D. H. CLARK, and F. D. LEE

Malabsorption of small doses of castor oil in patients with steatorrhoea W. C. WATSON

Intestinal malabsorption in Strongyloides stercoralis infestation P. F. MILNER, R. A. IRVINE, C. J. BARTON, G. BRAS, and R. RICHARDS
Control of the intestinal flora by means of antibacterial drugs in surgery of the colon A. A. GUNN and J. C. GOULD

Bacterial flora in intestinal amoebiasis F. P. ANTIA, H. G. Desai, P. M. ChapheKaR, R. H. ChHABRA, R. H. SWAMI, and A. V. BORKAR

Carbenoxolone sodium in the treatment of gastric ulcer with special reference to side-effects A. G. G. TURPIE and T. J. THOMSON

Influence of diet on occult blood tests D. G. ILLINGWORTH

Protein content of gastric juice D. W. PIPER, ELLENORE M. GRIFFITH, BARBARA H. FENTON, and DEBORAH BEESTON

Part I A study of the validity of the biuret reaction in determining protein concentration after peptic digestion and acid hydrolysis of protein

Part II In normal subjects and patients suffering from peptic ulcer and gastric carcinoma

Studies on intestinal $p \mathrm{H}$ by radiotelemetering w. c. WATSON and E. PATON

Methods and techniques

New technique for portal catheterization in dogs MAX RENDALL

Copies are still available and may be obtained from the PUBLISHING MANAGER 